\title{
Investigation of maximum Nusselt number with inclined and non-confined offset jet impingement cooling
}

\author{
Sunil B. Ingole ${ }^{1 *}$, Kalyan K. Sundaram ${ }^{2}$ \\ ${ }^{1}$ D. Y. Patil College of Engineering and Innovation, Pune 410506, India \\ ${ }^{2}$ IFM, Pune 410506, India
}

Corresponding Author Email: sbingole1@ @rediffmail.com

https://doi.org/10.18280/ijht.360513

Received: 28 September 2017

Accepted: 19 July 2018

\section{Keywords:}

convective cooling, maximum nusselt number, inclined jet, nonconfined jet, offset jet

\begin{abstract}
Inclined jet impingement is used for various industrial cooling applications. Its manufacturing and ease of applications is making it more popular day by day. The hot flat target surface is cooled using jet impingement. The jet is kept at an inclination of $15-75^{\circ}$ to hot target plate. The experiments are performed to study cooling effect with different configurations of inclined jets. Inclined jet with air as fluid having Reynolds number in the range of $2,000 \leqslant \operatorname{Re} \leqslant 20,000$ is examined for the circular cross section of jet. The target surface to jet perpendicular height $(\mathrm{H})$ is taken as $0.5 \leqslant \mathrm{H} / \mathrm{D} \leqslant 6.8$. The maximum cooled spots on the target surface are identified on the plate by analyzing maximum Nusselt numbers at different locations. The effect of $\mathrm{H}$ and $(\mathrm{H} / \mathrm{D})$ on maximum Nusselt number is presented. The investigation leads to equations for maximum Nusselt number for inclined circular non-confined air jet in terms of Reynolds number. Also analysis is carried out for ratio of average Nusselt number to maximum Nusselt number.
\end{abstract}

\section{INTRODUCTION}

In most of the cases, jet impingement fluids used are air compared to high heat transfer coefficient liquids. Mainly jets are classified as shown in Fig. 1. The classification presented is on the basis of different criterions as follows.

1. Based on fluid flow

a) Free jet, b) Submerged jet, c) Confined jet [1]

2. Based on inclination of jet

d) Perpendicular jet, e) Inclined jet, f) Projectile jet

3. Based on orientation of jet

g) Downward jet h) upward jet, i) Horizontal jet

Air jets are having capability to dissipate high heat flux and they can also care about hot spots, basically for even cooling solutions [2-3].

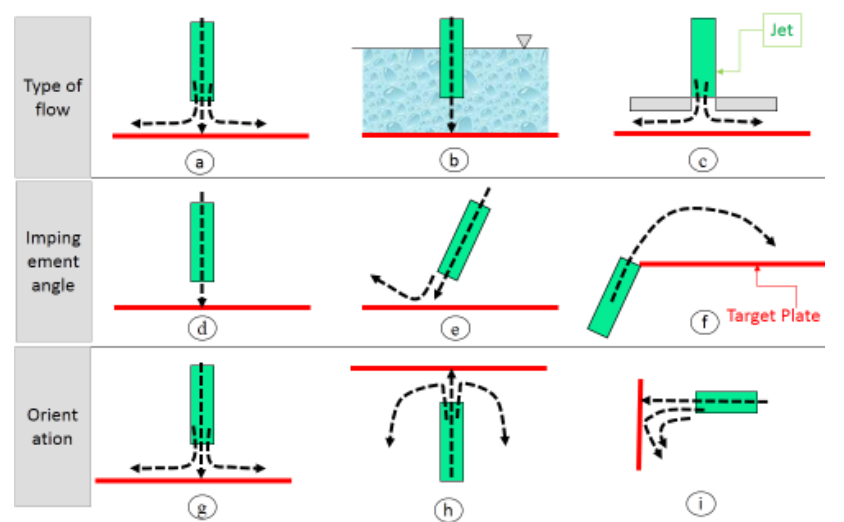

Figure 1. Types of jet

\section{LITERATURE SURVEY ON INCLINED JET}

It is observed that, numerical as well as experimental work has been performed by many authors. Jet velocity, jet cross section [4], placement of jet, position of target surface, fluid used in jet; are important parameters affecting performance of jet cooling. The hydrodynamics and heat transfer of unequal geometry of the tilted plane jet (of liquid with uniform and parabolic cross section) is solved using the Nervier-Stokes equations using a finite-volume method [5]. It is concluded that the maximum Nusselt number position and the maximum pressure position have been established to move upstream from the geometrical impingement point of the jet with the degree of the displacements growing as the inclination increases. The conclusion of jet inlet velocity profile has a significant effect on the heat transfer. Heat transfer characteristics in a channel is performed to understand effect of exit air from channel [6].

An experimental and numerical study was carried out to describe the isothermal laminar flow of a liquid jet restricted by inclined plane walls which was originating from a rectangular duct [7]. Experimental investigation is performed for observing the heat transfer features of impinging circular jet at $90^{\circ} \leq \mathrm{e} \leq 150^{\circ}$ from bottom [8] by using three Reynolds numbers; 2,800; 9,000; and 36,000 and 'jet-to-plate distance' to 'jet diameter' ratio $\mathrm{H} / \mathrm{D}$ as 5,10 , and 15 . It is observed that inclination was most effective parameter. The position of the stagnation point changes with change of inclination angle for high Reynolds number. Also investigation of inclined vertical surface characteristics by using horizontal air jet is carried out, and giving different heat transfer characteristics [9].

Cooling investigation experiments can also be performed in wind tunnel. The study is carried out for cooling applications with a single tilted $\left(90^{\circ}, 60^{\circ}, 45^{\circ}\right.$ and $\left.30^{\circ}\right)$ air jet (with $\mathrm{Re}$ of 
5,860, 8,879, and 11,606) [10]. By experimental study, a correlation is presented in terms of temperature ratio as a function of Reynolds number, dimensionless distance, and oblique angle ( $\operatorname{Sin} \Theta)$. The jets can be used for cooling as well as heating. The thermal features on an inclined plate $\left(0^{\circ}\right.$ to $\left.30^{\circ}\right)$ for heating application is investigated. The jet impinged is an under expanded sonic jet of hot fluid, examined with effect of nozzle (with $\mathrm{D}=10 \mathrm{~mm}$ ) to space distance [11]. The 'inclinations of jet' is defined by various authors by different perspective, which may have to be studied before understanding actual phenomenon.

As perpendicular jet, in inclined jet also, the cross section geometry of jet matters and variations are observed in literature. Slot air jet with the inclined $\left(0^{\circ}\right.$ to $\left.40^{\circ}\right)$ experimentally is verified and concluded as average Nusselt numbers at this condition increase as the inclination angle increases. But it decreases at higher spacing, due to momentum loss of the wall jet [12].

The surface to be cooled (its texture, convexity-concavity, and position/placement) are of equal importance, as it directly led to changes in flow pattern of fluid when it will be coming out of jet. If also, majority used air as fluid, transformer oil is investigated in the jet with the vertical heated surface to an inclination $\left(90^{\circ}\right.$ to $\left.45^{\circ}\right)$ of circular free-surface jet (Reynolds number between 235 and 1,745). It is observed as maximum heat transfer coefficient was decreases with the increasing of jet angle [13]. Inclined jet is investigated heat transfer characteristics with inclination of $\left(0^{\circ}\right.$ to $\left.60^{\circ}\right)$ jet (with Reynolds number 5,000) and H/D of 3 to 7 . The conclusion leads to the maximum Nusselt number decreases as inclination increases and the Nusselt number peak position shifts towards the uphill side until inclination of $45^{\circ}$ and shifts back for jet inclination of less than $45^{\circ}$ [14]. Two inclined jets for different geometry are also investigated [15].

During inclined jet study of jet (Reynolds number of 10,000 to 35,000$)$, and the oblique angle $\left(60^{\circ}\right.$ to $\left.90^{\circ}\right)$, a correlation is presented for maximum Nusselt number [16]. laminar flow heat transfer with a pair of $1 \mathrm{~cm}$ wide inclined confined impinging air jets (Reynolds number of 300 and 600) at the center of a channel for the application of electronics PCB cooling is studied and concluded that the behavior of jet largely governed by on the closeness of the jet inlets, the channel size and jet Reynolds number [17].

Jets are complicated in flow behavior and thus 3-D study is also performed [18]. For simplicity, 2D jets are also considered by some of the authors. Numerically studied (2D) jet to find heat transfer rate using CFD is also presented. Unconfined submerged jet is used and it's inclined with an angle of $40^{\circ}$ to $90^{\circ}$ with jet flow having Reynolds number in range of 4,000-16,000 discharged from a slot nozzle to flat and inclined plate for H/D spacing of 4-10 for CFD analysis [19]. A downward facing inclined wall, heated by Joule effect, and air in the presence of small air pulsating jets is tested with and without pulsating jets [20]. The hot object which is to be cooled jet is placed in moving position than stationary [21]. Also two inclined jets are being tried experimentally study the effect of the inclination angle of air jets on heat transfer from a horizontal surface. The inclination angles of $0^{\circ}, 10^{\circ}, 20^{\circ}, 30^{\circ}$ $45^{\circ}$, and $60^{\circ}$ are selected while the Reynolds number is varied from 10,000 to 40,000 based on a jet exit diameter. The experimental results show that the maximum magnitude of average heat transfer coefficient is achieved in the range of inclination angle from $10^{\circ}$ to $20^{\circ}$ [22]. The high temperature target surface is cooled by air jet impinged at an inclination of $15-75^{\circ}$. Air Inclined jet with Reynolds number in the range of $2,000 \leqslant \operatorname{Re} \leqslant 20,000$ is examined for the circular Inclined jet. The target surface to inclined jet perpendicular height $(\mathrm{H})$ is varied from $0.5 \leqslant \mathrm{H} / \mathrm{D} \leqslant 6.8$ for understanding effect of $\mathrm{H}$ on cooling performance of different locations on target plate. The investigation leads to equations for average Nusselt number for inclined non-confined air jet for cooling applications [23]. It is observed that, inclined jet is comparatively neglected area, because of which probably perpendicular jet systems and applications for cooling are established commonly [5]

Objective and scope of current study is to investigate and understand effect of offset jet impingement cooling by use of inclined air jet at Reynolds numbers for the range of 2,000 to 20,000. The effect of 'target surface to jet distance' with different angles on 'maximum Nusselt number' is presented which have been obtained by experimentation. By this the equation can be developed which can be useful for finding out maximum Nusselt number for any such case of inclined jet with specific physical and flow parameters.

\section{PROPOSED EXPERIMENTATION}

Inclined jet cooling has many influencing parameters; and most influencing are: hydraulic diameter of jet, target surface to jet height, convective heat transfer coefficient, thermal conductivity of fluid, velocity of fluid coming out of jet, kinematic viscosity, density of fluid, specific heat, temperatures, geometrical stagnation distance measured from leading edge $[24,2]$.

$N u=f\left(\frac{H}{D}, \operatorname{Re}, \operatorname{Pr}, \theta\right)$

Assumptions are made during experimentation and they are heat supplied to target plate is constant; negligible heat loss by conduction through the target plate, as the plate is very thin; Material of the target plate is isotropic and homogeneous.

Air is used as working fluid, hence for analysis it is assumed that Prandtl number is constant, and is not considered in presented equations. But if fluid is changed, effect of Prandtl number to be considered. Heat transfer from bottom is by natural convection. By considering these assumptions, an experimental setup is designed as shown in Fig. 2.

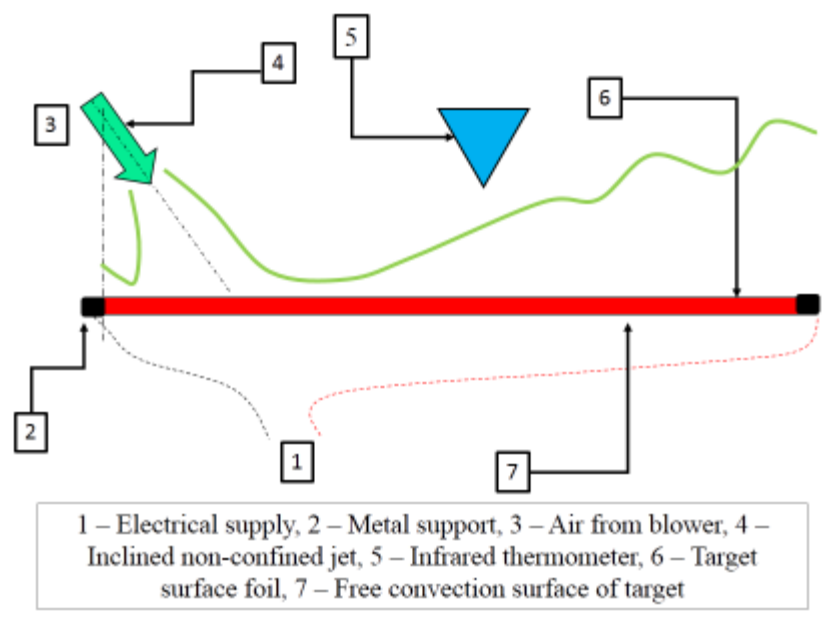

Figure 2. Experimental layout 


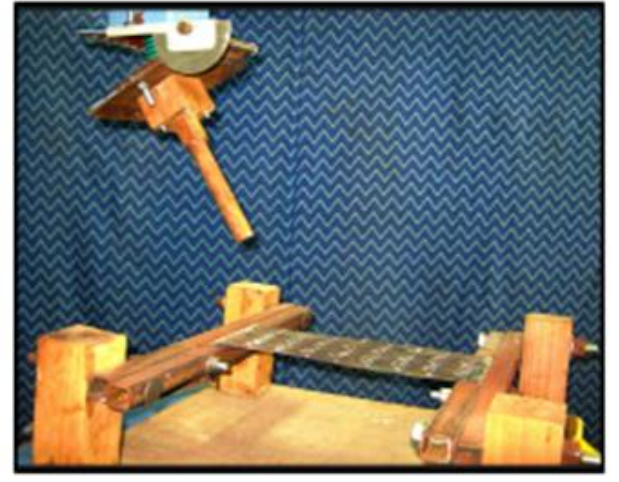

Figure 3. Image of experimental arrangement

The air jet is generated by using blower and impinged on the target plate. The target plate surface is positioned horizontal. The target surface is hot, plane and smooth plate, which is made up from thin foil of stainless steel with thickness of $0.05 \mathrm{~mm}$ and it is heated by Joule's effect. To avoid buckling of target plate, the provision is made to tighten the foil using tightening arrangement available with housing of target plate. [25-26]. The housing is made up so as to position the target plate as per required location of jet. The arrangement is made for changing distance of jet from target surface $(\mathrm{H})$. The single phase AC electric supply is provided to plate using copper bus bars ( 3 Volt and 50 Ampere). The jet is made up of circular cross section and of wood and plastic for the purpose of cooling target surface. The photograph of actual setup is shown in Fig. 3. The bottom side of plate was not impinged with jet and it is allowed to cool by natural convection. For cooling of target plate, atmospheric air is used as a fluid in present study. Air is impinged by a blower with circulating pipe at Reynolds number from 2,000 to 20,000. The target surface in this case is to analyze maximum Nusselt number obtained during experimentation.

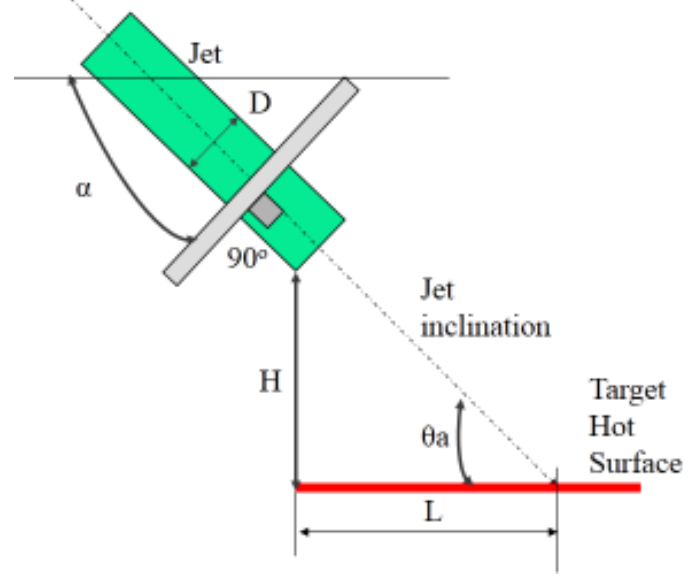

Figure 4. Inclined offset jet nomenclature

The axis of jet can make an angle of $0^{\circ}$ to $90^{\circ}$ with horizontal target plate as shown in Fig. 4. Fig is also showing $\theta \mathrm{a}$ as an actual jet inclination with target surface, whereas $\theta \mathrm{p}$ is perpendicular jet impingement i.e. $90^{\circ}$. It is assured that target plate is horizontal and it makes right angle to vertical jet pipe by using Engineer's square and sprit level.

Based on the literature available, experiment is designed and investigation is conducted with the intention of cooling of entire target surface, with comprehensive / collective cooling approach of electronics devices. It is to be specially noted that jet is not impinged at the center of the plate, but placed at vertical plane, in line with edge of the target plate i.e. on leading edge, which can also be called as 'offset cooling'. Results of average Nusselt number are presented in [23] and used in this paper further as a reference. The data reduction is made as per following equations.

Heat supplied to the target plate is by supply of electricity, hence energy supplied is;

Energy Supplied $=$ VI

$E_{\text {in }}=V I$

The energy taken out by jet impinged is,

$E_{\text {out }}=Q_{\text {conv.top }}+Q_{\text {conv.bottom }}$

where, bottom side of target surface is to be cooled by natural convection. $Q_{\text {conv.bottom }}=$ Natural convection

And is calculated as,

$Q_{\text {conv.bottom }}=h \cdot A \cdot \Delta T$

Finally, energy supplied to target surface is,

Total energy supplied $=V I-Q_{\text {conv.bottom }}$ i.e. i.e. $\left(Q_{\text {actual }}\right)=V I-Q_{\text {conv.bottom }}$

The objective is to calculate maximum Nusselt number i.e. $\mathrm{Nu}_{\max }$. For this first local Nusselt number is to be calculated on entire plate. The target plate is located with number of cross markers on the flat surface, and each of these position, local Nusselt number is calculated.

$$
\begin{aligned}
& N_{u}=\frac{h D}{k} \\
& Q_{a c t}=h \cdot A \cdot \Delta T \\
& h=\frac{Q_{a c t}}{A \cdot \Delta T} \\
& N_{u}=\frac{Q_{a c t}}{A \cdot \Delta T} \cdot \frac{D}{k} \\
& N_{u}=\frac{\left(\text { VI-Q } Q_{\text {conv.bottom }}\right)}{A \cdot \Delta T} \cdot \frac{D}{k}
\end{aligned}
$$

Table 1. Uncertainty analysis

\begin{tabular}{cccc}
$\mathbf{S}$. & Parameter & Symbol & Uncertainty \\
$\mathbf{N}$ & Diameter of jet & $\mathrm{D}$ & $2.5 \%$ \\
\hline 1 & Height of jet to target & $\mathrm{H}$ & 1.8 to $10 \%$ \\
2 & Jet Air Velocity & $\mathrm{V}$ & 0.49 to $2.3 \%$ \\
3 & I & $5 \%$ \\
4 & Current to heater & $\mathrm{V}$ & $0.18 \%$ \\
5 & Voltage to heater & $\mathrm{T}$ & $0.5 \%$ \\
6 & Temp. of heater plate & $\mathrm{\Theta}$ & 1.33 to $6.6 \%$ \\
7 & Angle of jet inclination & $\mathrm{X}$ & $0.37 \%$ \\
8 & Length of target plate & $\mathrm{Y}$ & $0.94 \%$ \\
9 & Width of target plate & $\mathrm{Re}$ & 6.6 to $4.4 \%$ \\
10 & Reynolds Number & $\mathrm{Q}$ & $5 \%$ \\
11 & Heat supplied & $\mathrm{Nu}$ & 5.67 to $8.0 \%$ \\
12 & Nusselt Number & & \\
\hline
\end{tabular}

After calculating local Nusselt number at various locations on target plate, $\mathrm{Nu}_{\max }$ is to be identified. The common curve 
fitting process is used with reference to $\mathrm{R}$ squared value. The experimental uncertainty calculated by conventional method and is as shown in Table 1.

\section{MAXIMUM NUSSELT NUMBER: ANALYSIS, RESULTS AND DISCUSSION}

Maximum Nusselt number signifies the effectiveness of cooling system, specifically in the view of hot spot cooling. It can be applied for numerous cooling applications; particularly in electronic systems. Generally, inclined jet cooling systems are used for homogeneousness in cooing the target surface, it is also important to know the cooling pattern across the target plate. It has its unique importance, as during cooling process the hot and cold spots are generated on target surface. Nusselt number is calculated as per process explained in section 1.3. Total forty number of points are identified on the target surface in the form of X-Y matrix. [23] At such every point, Nusselt number is calculated and maximum Nusselt number is identified. The position of maximum Nusselt number is also considered as the area of analysis to understand hot spot and cold spot positions on target surface, which is not in scope of presented study, but given in [27]
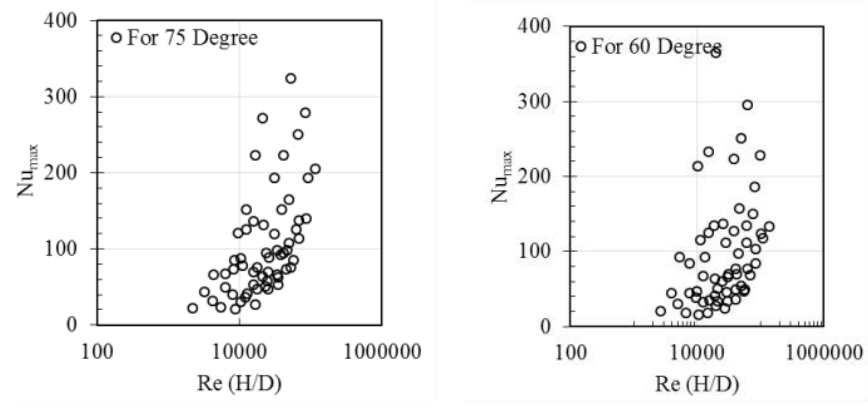

a) $75^{0}$
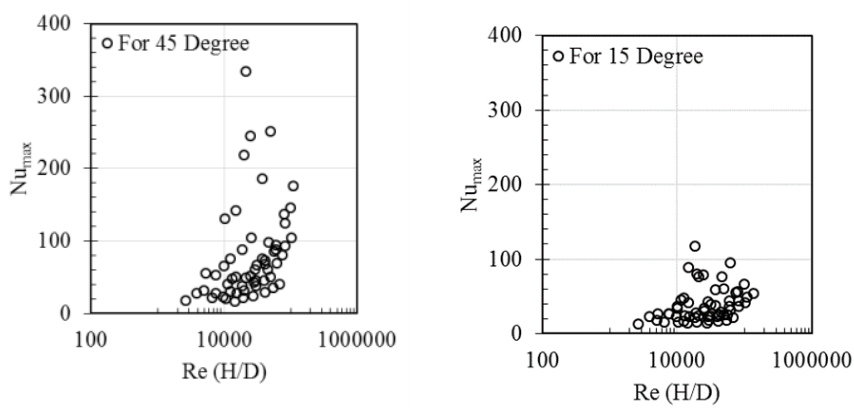

c) $45^{0}$

d) $15^{0}$

Figure 5. $\mathrm{Nu}_{\max }$ variation for specific jet inclination

Jet impingement at various inclinations is experimentally performed and data collected is processed as above. The effect of inclination of jet impingement on maximum Nusselt number, for different variations and combinations of Reynolds number and H/D are presented in Fig. 5. Figure is showing maximum Nusselt number for jet inclinations from $15^{\circ}$ to $75^{\circ}$. As range selected within $0^{\circ}$ to $90^{\circ}$, the four angles within the range are selected for experimentation. It is observed that, various operational parameters are dominating each other and by then heat transfer also, hence it will be difficult to conclude about the combination of parameters which is giving maximum Nusselt number for wide range of experimentation which are under study. It is to be noted that, all this data plotted is for entire range of experimentation, typically for Reynolds number and $(\mathrm{H} / \mathrm{D})$.

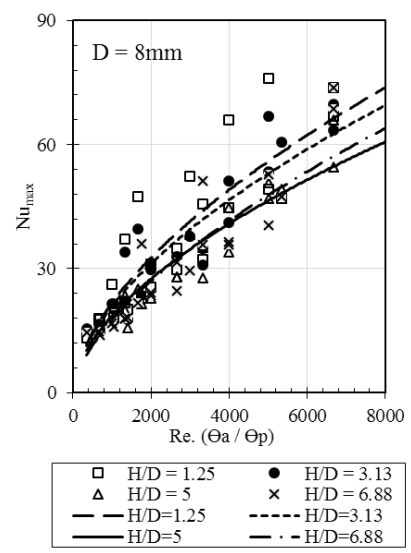

a) For $\mathrm{D}=\mathbf{8} \mathrm{mm}$

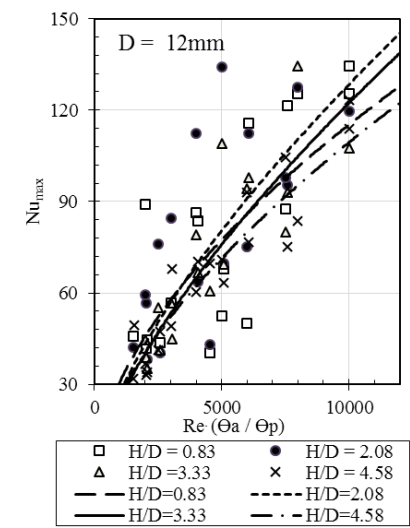

b) For $D=12 \mathrm{~mm}$

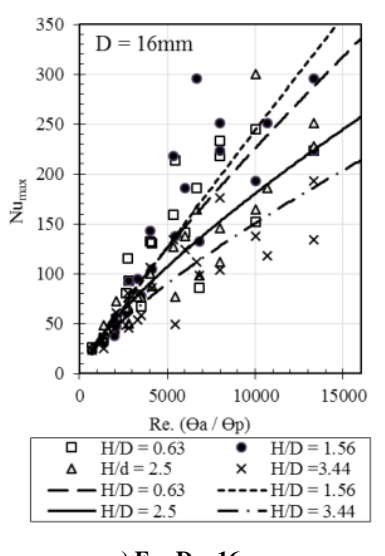

Figure 6. Variations of $\mathrm{Nu}_{\max }$ at different (H/D)

For inclinations of $75^{\circ}$ and $60^{\circ}$ almost the performance is similar and getting maximum $\mathrm{Nu}_{\max }$ up to 300 , by producing cold spots on target surface. For $45^{\circ}$ jet impingement, the maximum $\mathrm{Nu}_{\max }$ is widely spread. But majority of points on graph are in the zone up to 150 , as same as that of jet inclination of $30^{\circ}$. For $15^{\circ}$ of jet impingement, the frequency of getting $\mathrm{Nu}_{\max }$ up to 80 is maximum, which can be realized by observing crowded locations on plots as in the Fig. 5 (d), and thus gives poor cooling.

\subsection{Maximum Nusselt number with reference to $h / d$}

Jet height from target surface is defined earlier in Fig. 4. The height $\mathrm{H}$ will decide exact location of jet impingement, as well as flow lines which gets propagated after impingement. Fig. 6 shows variation of maximum Nusselt number with respect to $\mathrm{H} / \mathrm{D}$ ratio for jet diameter of 8 to $16 \mathrm{~mm}$. These plots are made specially to understand effect of target surface to jet height only with reference to variations in jet diameters. It is concluded that as diameter increases, the maximum Nusselt number also increases drastically. This happens as Nusselt number is influenced majority by Reynolds number. After examination of different $\mathrm{H} / \mathrm{D}$ ratios, it is understood that lower height to diameter ratio up to 2 is giving highest $\mathrm{Nu}_{\max }$. The fact is as H/D increases, the maximum Nusselt number decreases, in agreement with [28]. The conclusion is validated by plot for fixed jet diameter of $8 \mathrm{~mm}$, for fixed jet inclination angle of $45^{\circ}$, as shown in Fig. 7. 


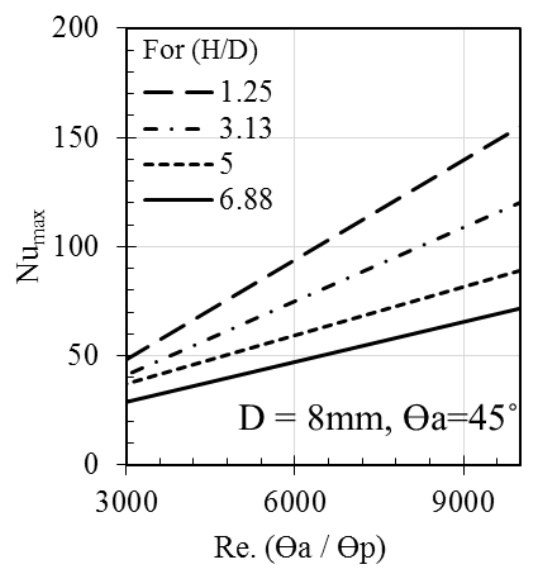

Figure 7. As (H/D) increases, $\mathrm{Nu}_{\max }$ decreases

But if jets with different diameters are considered and compared, it will be difficult to predict effect of (H/D) on maximum Nusselt number. This happens due to the fact that as $\mathrm{H}$ increases, effective cooling area changes, also Reynolds number changes due to change in diameter. This indicates that (H/D) is not only the parameter affecting maximum Nusselt number. Efforts are made to discuss effect of variation in $\mathrm{H}$ in next section. As distance between jet and target surface changes, the local, average and maximum Nusselt number is going to change accordingly. When target surface is near or far away from jet opening, it gives different velocity profiles after impingement.

\subsection{Maximum Nusselt number related to height of jet to target surface (h)}

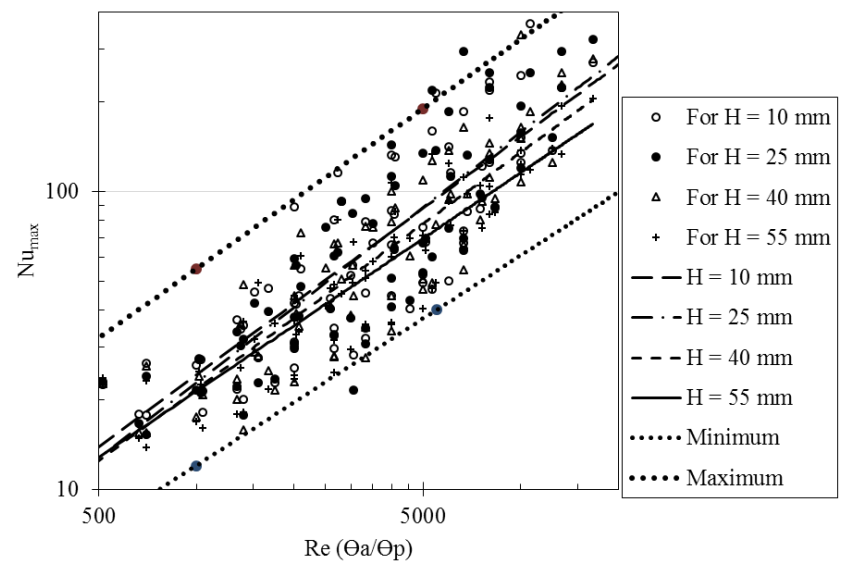

Figure 8. $\mathrm{Nu}_{\max }$ variation with target to jet height $(\mathrm{H})$

The objective is to analyze effect of variation of target surface to jet distance as the single affecting parameter. $\mathrm{H}$ considered during the experimentation as $10 \mathrm{~mm}, 25 \mathrm{~mm}, 40$ $\mathrm{mm}$ and $55 \mathrm{~mm}$ and its effect on $\mathrm{Nu}_{\max }$ is shown in Fig. 8. The kinetic energy within the impinged jet plays most significant role in cooling surface. Accordingly, plots are made as shown in Fig. 8. For all jet diameters under consideration, it is observed that with lesser target surface to height distance, higher $\mathrm{Nu}_{\max }$ is obtained. The performance of jet plotted shows that at $\mathrm{H}$ with $10 \mathrm{~mm}$ and $25 \mathrm{~mm}$, cooling performance related to maximum Nusselt number is approximately similar. With $\mathrm{H}$ as $40 \mathrm{~mm}$, the reduction in $\mathrm{Nu}_{\max }$ is obtained, and further it decreases for $\mathrm{H}$ with $55 \mathrm{~mm}$. This indicates that, for parameters under this study, $\mathrm{H}$ should be less than $25 \mathrm{~mm}$ for better cooing performance. As a conclusion, when the target surface to jet distance, $\mathrm{H}$ increases, the $\mathrm{Nu}_{\max }$ decreases; of which perfect trend is seen in Fig. 8.

\subsection{Maximum Nusselt number correlations}

It is significant to note the maximum value of Nusselt number, so that location of jets can be positioned during designing cooling systems, typically for hot spot cooling applications. It is observed that the maximum Nusselt number is maximum at highest Reynolds number. On the basis of jet inclination, the maximum Nusselt number is showing highest results close to Angle Ratio (AR) of 1 .

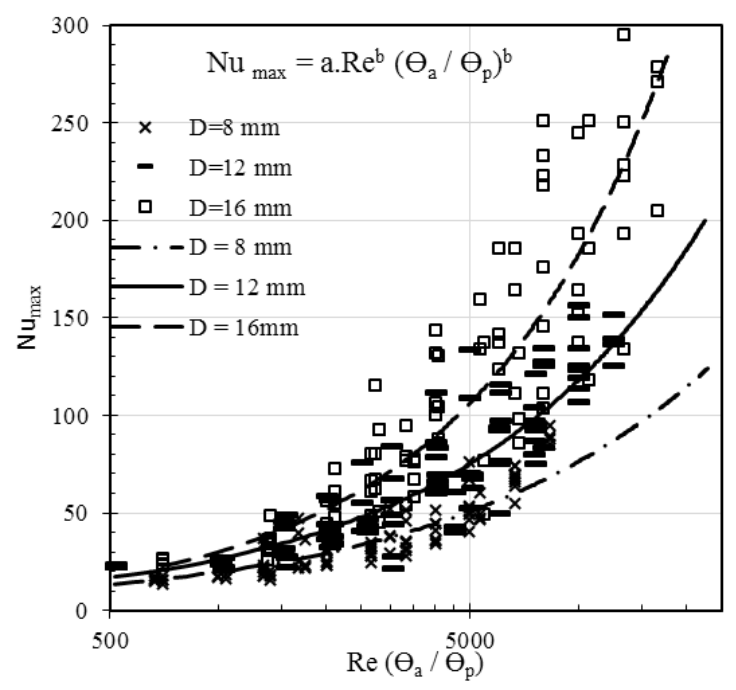

Figure 9. $\mathrm{Nu}_{\max }$ variations for variations in jet diameters

With the intention of developing a correlation of $\mathrm{Nu}_{\max }$, the Reynolds number is an important parameter, with obviously angle ratio. The objective is to find maximum cooling taking place on the target surface by knowing different parameters. For all values of $\mathrm{H}$ under study, different correlations are suggested for different jet diameters as in Fig. 9. Two form of equations are suggested by regression analysis of data available by experimentation under study. These will be helpful to locate the position of hottest surface / component placement while designing electronics packaging

The first form is:

$N u_{\max }=a \cdot R e^{b} \cdot\left(\frac{\theta_{a}}{\theta_{p}}\right)^{b}$

The values of constant ' $a$ ' and ' $b$ ' suggested are shown in Table 2.

Table 2. Constants a and $\mathrm{b}$ for equation (11)

\begin{tabular}{cccc}
\hline \hline $\mathbf{D}(\mathbf{m m})$ & $\mathbf{a}$ & $\mathbf{b}$ & $\begin{array}{c}\text { R-Squared } \\
\text { value }\end{array}$ \\
\hline \hline 8 & 0.3364 & 0.5887 & 82.9 \\
\hline 12 & 0.2934 & 0.6509 & 81.1 \\
\hline 16 & 0.1379 & 0.7803 & 84.8 \\
\hline \hline
\end{tabular}

The second form of equation suggested is equation (12) and the constants 'a', 'b', 'c' are suggested in Table 3.

$N u_{\max }=a \cdot R e^{b} \cdot(c)\left(\theta_{a} / \theta_{p}\right)$ 
Table 3. Constants a, b and c for equation (12)

\begin{tabular}{cccc}
\hline $\mathbf{D}(\mathbf{m m})$ & $\mathbf{a}$ & $\mathbf{b}$ & $\mathbf{c}$ \\
\hline 8 & 0.0159 & 0.81 & 3.76 \\
12 & 0.0287 & 0.79 & 3.12 \\
16 & 0.0195 & 0.87 & 3.06 \\
\hline
\end{tabular}

Both the equations suggested are giving close results with better agreement level of $+/-25 \%$ as shown in Fig. 10 (For sample case of $8 \mathrm{~mm}$ jet diameter). The conclusions agree with the fact that maximum Nusselt number occurs downstream of intersection of nozzle axis and target surface [29].

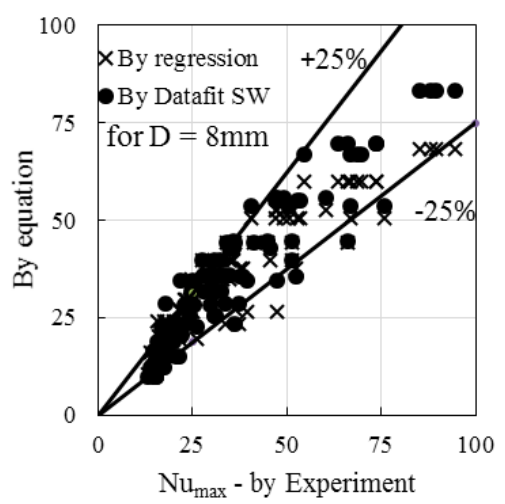

Figure 10. Evaluation of results by equation and experiment

\subsection{Maximum Nusselt number related with (Xo/d)}

Maximum Nusselt number is analyzed in this section related to $(\mathrm{Xo} / \mathrm{D})$, in which $\mathrm{Xo}$ is the geometrical stagnation distance, and defined as horizontal distance where axis of jet is intersecting on flat target plate. Similar trend, as that of average Nusselt number is observed and shown in Fig. 11. The maximum Nusselt number is the function of Xo or jet inclination angle.

By using angle as a parameter the study is carried in next section. But as per dimensional analysis, $(\mathrm{Xo} / \mathrm{D})$ is considered specifically in this section. As (Xo/D) increases, i.e. angle of inclination decreases, the maximum Nusselt number decreases. By available space during packaging of electronics systems, once location of jet is decided, it could be possible to fix inclination depending upon need of cooling requirement. The suggested equation for maximum Nusselt number is as (13) and Valid for (Xo/D) up to 30.

$N u_{\max }=120.92\left(\frac{X_{0}}{D}\right)^{-0.503}$

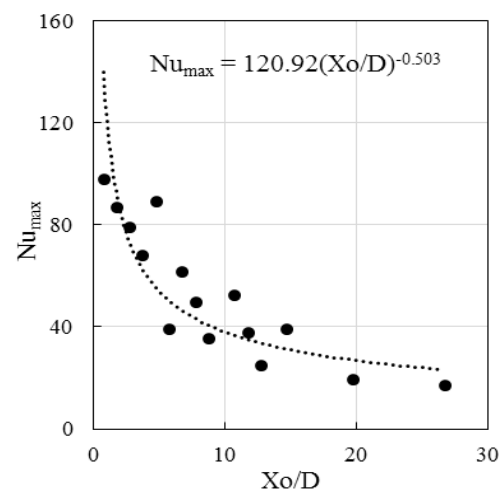

Figure 11. Trend of $\mathrm{Nu}_{\max }$ with $(\mathrm{Xo} / \mathrm{D})$

\section{$4.5\left(\mathrm{Nu}_{\mathrm{avg}} / \mathrm{Nu}_{\max }\right)$ analysis}

The analysis of $\left(\mathrm{Nu}_{\mathrm{avg}} / \mathrm{Nu}_{\max }\right)$ is performed to understand pattern of variation with respect to jet inclination as shown in Fig. 12. In presented study $\mathrm{Nu}_{\text {avg }}$ is from [23] and the variation for $8 \mathrm{~mm}$ jet diameter is presented only. As expected, at an inclination of $75^{\circ}$, the ratio is observed to be 1 at lowest $\mathrm{X} / \mathrm{D}$. At $45^{\circ}$ angle, it is highest at $\mathrm{X} / \mathrm{D}$ of 10 , and it moves to $\mathrm{X} / \mathrm{D}=$ 25 for inclination of $15^{\circ}$.

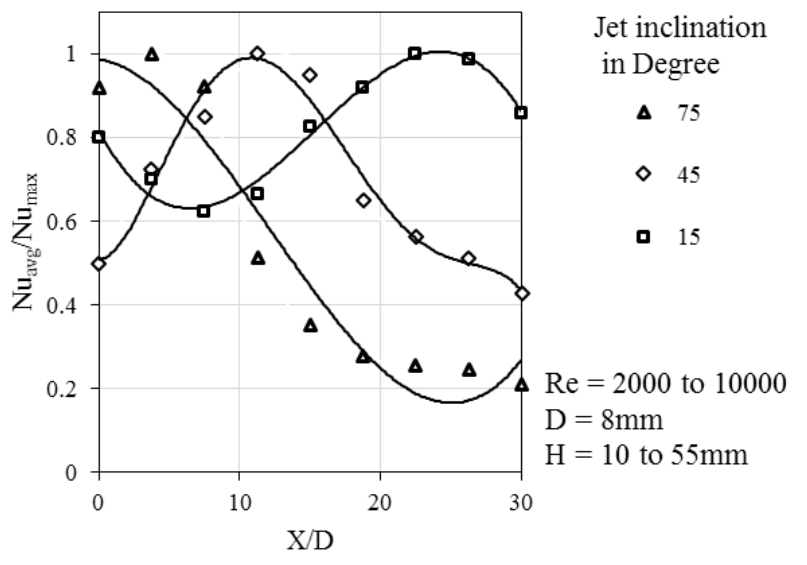

Figure 12. $\left(\mathrm{Nu}_{\mathrm{avg}} / \mathrm{Nu}_{\max }\right)$ verses $(\mathrm{X} / \mathrm{D})$ for $\mathrm{D}=8 \mathrm{~mm}$

Similar analysis is performed by changing jet diameter to 16 $\mathrm{mm}$ with the intention of understanding effect of variation in diameter. The variation in Nu ratio is shown in Fig. 13. It is observed that the pattern is comparable, but numerical values are fluctuating. For $16 \mathrm{~mm}$ diameter of jet, same pattern of graph as that of $8 \mathrm{~mm}$ is observed for jet inclination of $15^{\circ}$. Also the Nusselt number on target surface decreases lengthwise the wall in the direction of fluid flow typically for inclined jet as stated in [19]. If both the Fig. 12 and Fig. 13 are compared, $\left(\mathrm{Nu}_{\text {avg }} / \mathrm{Nu}_{\max }\right)$ is found to be 1 at $\mathrm{X} / \mathrm{D}$ of $0,12,24$ for jet diameter of $8 \mathrm{~mm}$ and $0,6,15$ for jet diameter of $16 \mathrm{~mm}$ (for $75^{\circ}, 45^{\circ}, 15^{\circ}$ jet inclination respectively). The alternative to conclude is, as diameter increases, (X/D) decreases for a particular jet inclination. Also highest $\left(\mathrm{Nu}_{\mathrm{avg}} / \mathrm{Nu}_{\max }\right)$ ratio is obtained (in $16 \mathrm{~mm}$ jet) at lesser (X/D) compared to $8 \mathrm{~mm}$ jet. But the analysis of $16 \mathrm{~mm}$ jet is at Reynolds number of 4,000 to 20,000 , which is the higher range compared with the earlier jet of $8 \mathrm{~mm}$ with Reynolds number of 2,000 to 8,000. This concludes that as Reynolds number increases, the maximum Nusselt number shifts nearer to leading edge. Also its value increases with Reynolds number and agrees with [19].

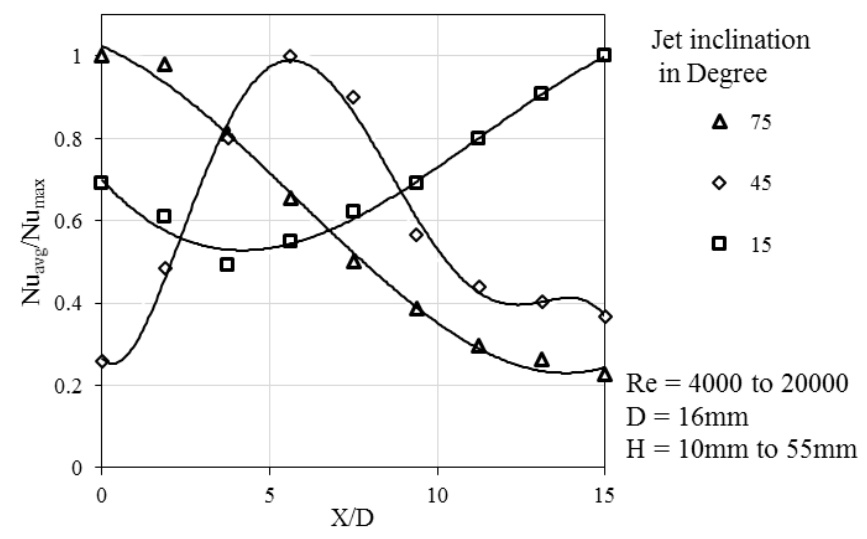

Figure 13. $\left(\mathrm{Nu}_{\mathrm{avg}} / \mathrm{Nu}_{\max }\right)$ verses $(\mathrm{X} / \mathrm{D})$ for $\mathrm{D}=16 \mathrm{~mm}$ 


\section{CONCLUSION}

The inclined jet cooling investigation is carried out by offset cooing using air as cooling fluid. The scope is limited to investigate maximum cooling taking place on target surface. It can be concluded that for inclinations of $75^{\circ}$ and $60^{\circ}$ almost the performance is similar and getting maximum $\mathrm{Nu}_{\max }$ up to 300 , by producing cold spots on target surface. For $45^{\circ}$ jet impingement, the maximum $\mathrm{Nu}_{\max }$ is widely spread. It is clearly observed that as jet inclination angle increases from $0^{\circ}$ to $90^{\circ}, \mathrm{Nu}_{\max }$ also increases. Also as jet diameter increases, the maximum Nusselt number increases drastically. Once jet strikes on the target surface, the Nusselt number on target surface reduces along the wall in flow direction. It is also an important task to understand location of maximum Nusselt number on target surface, which is not in the consideration of presented work.

\section{REFERENCES}

[1] Anandan SS, Ramlingam V. (2008). Thermal management of electronics: A review of literature. Thermal Science 12(2): 5-26. http://dx.doi.org/10.2298/TSCI0802005A

[2] Ingole SB, Sundaram KK. (2012). Review of experimental investigation in heat transfer for jet impingement cooling. International Review of Mechanical Engineering 6(3): 346-356.

[3] Ingole SB. (2017). Heat transfer analysis for multiple jet cooling of high temperature electronics target. International Conference on Intelligent Computing and Control Systems, http://dx.doi.org/10.1109/ICCONS.2017.8250713

[4] Sriromreun P, Sriromreun P. (2018). Experimental and numerical studies of heat transfer characteristics for impinging jet on dimple surfaces. Chemical Engineering Transactions $\quad 70: \quad 1273-1278$. http://dx.doi.org/10.3303/CET1870213

[5] Tong AY. (2003). On the impingement heat transfer of an oblique free surface plane jet. International Journal of Heat and Mass Transfer 46: 2077-2085. http://dx.doi.org/10.1016/S0017-9310(96)00310-9

[6] Ali A, Mubarak AL, Syed M, Shaahid Luai M, Hadhrami AL. (2013). Heat transfer in a channel with inclined target surface cooled by single array of centered impinging jet. Thermal Science 17(4): 1195-1206. http://dx.doi.org/10.2298/TSCI110630010A

[7] Cavadas AS, Pinho FT, Campos JBLM. (2012). Laminar flow field in a viscous liquid impinging jet confined by inclined plane walls. International Journal of Thermal Sciences 59: 95-110 http://dx.doi.org/10.1016/j.ijthermalsci.2012.04.004

[8] Hakan F, Varol OY, Koca A, Firat M, Turan B, Metin I. (2011). Experimental investigation of cooling of heated circular disc using inclined circular Jet. International Communications in Heat and Mass Transfer 38: 9901001 .

http://dx.doi.org/10.1016/j.icheatmasstransfer.2011.04.0 13

[9] Decker K, Rodrigo, Buss, Lizoel, Wiggers R, Vinicyus, Noriler, Dirceu, Reinehr L, Edelberto, Meier F, Henry, Martignoni, Waldir, Mori, Milton. (2011). Numerical validation of a coaxial and confined jet flow. Chemical
Engineering Transactions 24: 1459-1464. https://doi.org/10.3303/CET1124244

[10] Eren H, Celik N. (2006). Cooling of a heated flat plate by an obliquely impinging slot jet. International Communications in Heat and Mass Transfer 33: 372-380. http://dx.doi.org/10.1016/j.icheatmasstransfer.2005.10.0 09

[11] Song J, Lee JW, Yu MS, Shin SW, Kim BS, Cho HH. (2013). Thermal characteristics of inclined plate impinged by underexpanded sonic jet. Int. Journal of Heat and Mass Transfer 62: 223-229. https://doi.org/10.1016/j.ijheatmasstransfer.2013.02.066

[12] Choo K, Kang TY, Kim SJ. (2012). The effect of inclination on impinging jets at small nozzle-to-plate spacing. Int. Journal of Heat and Mass Transfer 55: $3327-$ 3334.

http://dx.doi.org/10.1016/j.ijheatmasstransfer.2012.02.0 62

[13] Ma CF, Zheng Q, Wu K. (1997). Local characteristics of impingement heat transfer with oblique round free surface jets of large Prandtl number liquid. Pergamon International Journal of Heat and Mass Transfer 40(10): 2249-2259. http://dx.doi.org/10.1016/S00179310(96)00310-9

[14] Kito M. (2012). Effect of inclination of impinging jets on flow and heat transfer characteristics. International Journal of Science and Engineering Investigations 1(9): 42-47.

[15] Nakabe K, Fornalik E, Jens F, Eschenbacher Yamamoto Y, Ohta T, Suzuki K. (2001). Interactions of longitudinal vortices generated by twin inclined jets and enhancement of impingement heat transfer. International Journal of Heat and Fluid Flow 22: 287-292. http://dx.doi.org/10.1016/S0142-727X(01)00090-X

[16] Yoon SH, Kim MK, Lee DH. (1997). Turbulent flow and heat transfer characteristics of a two-dimensional oblique plate impinging jet. KSME International Journal 11(4): 476-483. http://dx.doi.org/10.1007/BF02945086

[17] Chiriac VA, Rosales JL. (2004). The cooling impact of a pair of confined angled air jets impinging on a printed circuit board. In IEEE Inter Society Conference. http://dx.doi.org/10.1109/ITHERM.2004.1319236

[18] Yang YT, Wang YX. (2005). Three-dimensional numerical simulation of an inclined jet with cross-flow. Int. Journal of Heat and Mass Transfer 48: 4019-4027. http://dx.doi.org/10.1016/j.ijheatmasstransfer.2005.04.0 18

[19] Ramezanpour A, Shirvani H, Mirzaee I. (2003). A numerical study on the heat transfer characteristics of two-dimensional inclined impinging jet. In Electronics Packaging Technology Conference. http://dx.doi.org/10.1109/EPTC.2003.1271594

[20] Bartoli C. (2011). Free convection enhancement between inclined wall and air in presence of expired jets at temperature difference of $40 \mathrm{~K}$. Experimental Thermal and Fluid Science 35: 283-290. http://dx.doi.org/10.1016/j.expthermflusci.2010.09.010

[21] Benmouhoub D, Mataoui A. (2014). Inclined plane jet impinging a moving heated wall. Fluid Dynamics and Materials Processings 10(2): 241-260.

[22] Attallaa M, Hussein M, Spechtb ME. (2017). Effect of inclination angle of a pair of air jets on heat transfer into the flat surface. Experimental Thermal and Fluid Science 85:

85-94. 
http://dx.doi.org/10.1016/j.expthermflusci.2017.02.023

[23] Ingole SB, Sundaram KK. (2016). Experimental average Nusselt number characteristics with inclined nonconfined jet impingement of air for cooling application. Experimental Thermal and Fluid Science 77: 124-131. http://dx.doi.org/10.1016/j.expthermflusci.2016.04.016

[24] Ingole SB, Sundaram KK. (2015). Heat transfer enhancement factor characteristics for collective cooling using inclined air jet. 17th IEEE Electronics Packaging Technology Conference, pp. 1-6. http://dx.doi.org/10.1109/EPTC.2015.7412395

[25] Ianiro A, Cardone G. (2012). Heat transfer rate and uniformity in multichannel swirling impinging jets. Applied Thermal Engineering 49: 89-98. http://dx.doi.org/10.1016/j.applthermaleng.2011.10.018

[26] Imbriale M, Panelli M, Cardone G. (2012). Heat transfer enhancement of natural convection with ribs. Quantitative Infrared Thermography Journal 9(1): 55-67. http://dx.doi.org/10.1080/17686733.2012.681881

[27] Ingole Sunil B, Sundaram KK. (2017). Cold zone exploration using position of maximum nusselt number for inclined air jet cooling. Archive of Mechanical Engineering 64(4): 533-550. http://dx.doi.org/10.1515/meceng-2017-0031

[28] O'Donovan TS, Murray DB. (2006). Effect of vortices on jet impingement heat transfer. Proceedings of the International Heat Transfer Conference 13th, pp. 12-32. http://dx.doi.org/10.1615/IHTC13.p16.190

[29] Zuckerman N, Lior N. (2006). Jet impingement heat transfer: Physics, correlations, and numerical modeling. Advances in Heat Transfer 39: 565-631. http://dx.doi.org/10.1016/S0065-2717(06)39006-5

\section{NOMENCLATURE}

$\begin{array}{ll}\text { a, b, c } & \text { Constants } \\ \text { A } & \text { Area }(\mathrm{m} 2) \\ \text { D } & \text { Diameter / Hydraulic diameter of jet }(\mathrm{m}) \\ \text { E } & \text { Energy (Watt) } \\ \text { H } & \text { Target surface to jet height }(\mathrm{m}) \\ \text { h } & \text { Convective heat transfer coeff. }(\mathrm{W} / \mathrm{m} 2 \mathrm{~K}) \\ \mathrm{I} & \text { Current }(\text { Amp) } \\ \mathrm{K} & \text { Thermal Conductivity }(\mathrm{W} / \mathrm{mK}) \\ \mathrm{T} & \text { Temperature }\left({ }^{\circ} \mathrm{C} \text { or K) }\right. \\ \mathrm{V} & \text { Voltage }(\text { Volt }) \\ \mathrm{X} & \text { Distance, along X Axis }(\mathrm{m}) \\ \mathrm{Xo} & \text { Geometrical Stagnation distance }(\mathrm{m})\end{array}$

\section{Greek symbols}

$\begin{array}{ll}\theta \mathrm{a} & \text { Actual angle (Degree) } \\ \theta \mathrm{p} & \text { Perpendicular angle (Degree) } \\ \Delta & \text { Difference }\end{array}$

\section{Non Dimensional terms}

$\begin{array}{ll}\mathrm{AR} & \text { Angle Ratio } \\ \mathrm{Nu} & \text { Nusselt number } \\ \mathrm{Pr} & \text { Prandtl number } \\ \mathrm{Re} & \text { Reynolds number }\end{array}$

\section{Subscripts / Superscript}

$\begin{array}{ll}\text { a } & \text { Actual } \\ \text { avg } & \text { Average } \\ \text { conv } & \text { Convection } \\ \max & \text { Maximum } \\ \min & \text { Minimum } \\ \mathrm{p} & \text { Perpendicular }\end{array}$

